\title{
Effects of progesterone and estradiol on the inflammatory and apoptotic markers of ovariectomized rats challenged with acute septic systemic inflammation
}

\author{
Sinan Subhi Farhan ${ }^{1}$, Samir Saad Mahgoub², Saad Abdulrahman Hussain ${ }^{3, *}$ \\ 'Faculty of Pharmacy, Al Rafidain University College, Baghdad, Iraq. \\ ${ }^{2}$ Department of Biochemistry and Molecular Biology, Faculty of Medicine, Al Minia University, Minya, Egypt. \\ ${ }^{3}$ Department of Pharmacology and Toxicology, Faculty of Pharmacy, Al Rafidain University College, Baghdad, Iraq.
}

\begin{tabular}{l}
\hline ARTICLE INFO \\
\hline Received on: $12 / 07 / 2019$ \\
Accepted on: 17/10/2019 \\
Available online: 03/12/2019
\end{tabular}

Key words:

Septic systemic inflammation, liver, estradiol, progesterone, apoptosis.

\begin{abstract}
The inflammatory responses during septic inflammation were affected by the differential role of progesterone and estrogen that demonstrated pro-inflammatory and anti-inflammatory roles. This study was designed to evaluate the differential effects of estradiol and progesterone supplementation on the inflammatory and apoptotic responses in an ovariectomized (OVX) rat model of acute systemic septic inflammation (SSI). This study was conducted on 60 female Wistar rats. $40 \mathrm{mg} / \mathrm{kg}$ estradiol and $5 \mathrm{mg} / \mathrm{kg}$ progesterone were given subcutaneous (s.c.) to OVX rats, after the induction of SSI through caecum puncture with a 21 -gauge needle. Serum levels of tumor necrosis factor- $\alpha$ (TNF- $\alpha), C$-reactive protein (CRP), Alanine transaminase (ALT), estradiol, and progesterone were evaluated; additionally, Inducible nitric oxide synthase (iNOS), Cyclooxygenase (COX)-II, and caspase-3 were evacuated in liver tissue homogenates using the Enzyme-linked immunosorbent assay (ELISA) method. In OVX rats challenged with SSI, serum TNF- $\alpha$, CRP, and ALT levels were significantly increased associated with a decrease in serum estradiol levels. They also showed overexpression of iNOS and increased the activity of COX-II and caspase-3 in the liver compared to non-OVX rats subjected to SSI. Supplementation with estradiol significantly decreases all serum and liver tissue markers of inflammation and decreased apoptosis. In contrast, in OVX rats supplemented with progesterone, SSI resulted in a significant increase in the studied markers. In conclusion, the supplementation of estradiol in OVX rats challenged with SSI significantly attenuated the systemic and liver inflammatory and apoptotic markers. Meanwhile, the supplementation with progesterone exacerbates the effects of the inflammatory markers and increases the tendency of apoptosis in the liver tissue.
\end{abstract}

\section{INTRODUCTION}

The inflammatory response during sepsis was associated with overexpression of different inflammatory markers including interleukin-6 (IL-6) and TNF- $\alpha$, which are involved early in the pathogenesis of septic shock, apoptosis, and tissue damage (Bohannon et al., 2012; Jedynak et al., 2012; Lowes et al., 2013). During the advanced stage of septic shock, the increase in hepatic

\footnotetext{
*Corresponding Author

Saad Abdulrahman Hussain, Department of Pharmacology and Toxicology, Faculty of Pharmacy, Al-Rafidain University College, Baghdad, Iraq.

E-mail: saad.hussain@ruc.edu.iq
}

functions results in excessive hepatocellular apoptosis, a critical step in acute hepatic failure that complicates systemic sepsis (Marshall, 2001). Estradiol and progesterone have various immunomodulatory impacts that may be effectively involved in the pathophysiology of sepsis (Dellinger et al., 2008). However, the effects of elevated levels of both hormones in the prediction of the severity and outcomes of acute hepatic injury during septic shock remain controversial (Angstwurm et al., 2005; Szalay et al., 2006). Several studies have investigated the differential effects of estradiol and progesterone on the systemic inflammatory responses of various organs and tissues. It has been reported that estrogen therapy in postmenopausal females increases the hepatic production of C-reactive protein (Cushman et al., 1999) and the expression of IL-6, suggesting a pro-inflammatory role (Herrington et al., 2001). Meanwhile, other 
investigators demonstrated contradictory results for estradiol in this regard (Sunday et al., 2006; Wakatsuki et al., 2004). Moreover, the effects of progesterone in systemic inflammation represent a lot of controversies. In one study, progesterone augments the outcome of experimental stroke (Rosano et al., 2000), while another study indicates that progesterone resolves oxidative stress, reduces the production of IL- 6 and TNF- $\alpha$, and ameliorates the sepsis syndrome (Aksoy et al., 2014). This study was designed to evaluate the differential effects of estradiol and progesterone supplementation on the inflammatory and apoptotic responses in an OVX rat model of acute septic inflammation.

\section{MATERIALS AND METHODS}

\section{Animals}

Sixty female Wistar rats (200-250 gm) were used in the study. The animals were housed in the animal house, Faculty of Medicine, Mu'tah University under standardized conditions of temperature and humidity with 12:12 hour light/dark cycle and fed standard rodent chow and tap water ad libitum. The study protocol was approved by the local Committee of Research Ethics (REC-345-2017) in compliance with the international standard care of experimental animals (Canadian Council on Animal care, updated in 2017).

\section{Study design}

The rats were randomly allocated to six groups (10 rats each) as follows: group I, served as a negative control group and subjected to Sham ovariectomy procedure (Sh-OVX); group II, a positive control where the Sh-OVX was followed by the induction of a septic systemic inflammation (SSI) 2 weeks later; group III, exposed to OVX followed by the induction of SSI 2 weeks later (Fink and Heard, 1990); group IV, after OVX, each rat was administered a daily subcutaneous (s.c.) estradiol dose of $40 \mathrm{mg} /$ $\mathrm{kg}$ body weight followed by the induction of SSI 2 weeks later; group $\mathrm{V}$, after OVX, each rat received $5 \mathrm{mg} / \mathrm{kg} /$ day progesterone s.c. followed by SSI induction 2 weeks later (Tsai and Legan, 2002); group VI, OVX is followed by the administration of a combination of estradiol and progesterone doses (as mentioned previously) followed by SSI induction 2 weeks later.

\section{Surgical intervention and induction of septic systemic inflammation}

After short anesthesia with diethyl ether, the rats in groups I and II were subjected to Sham OVX; while the rats in groups I-IV were subjected to bilateral ventral OVX followed by the hormonal supplementation (as mentioned above). In all rats (except group I), SSI was induced after 2 weeks. The induction of inflammation was performed by ileocecal ligation and punctured using a 21 -gauge needle. After 24 hours of sepsis induction, a blood sample was obtained through a direct cardiac puncture under mild anesthesia; then, the animals were euthanized to extract livers for the assay of the tissue markers of inflammation and apoptosis according to standard procedures (Aksoy et al., 2014).

\section{Measurements of markers}

The obtained blood samples were kept in plain tubes and left to clot. The collected sera were used for the assay of estradiol, progesterone, TNF- $\alpha$ (Mizutani et al., 2003), Alanine transaminase (ALT) activity, and C-reactive protein levels (Gewurz et al., 1982) using ready-made kits (Biomatic, Ontario, Canada). The rate of expression of Inducible nitric oxide synthase (iNOS) and the levels of Caspase-3 and Cyclooxygenase (COX)II in the liver tissue homogenates were analyzed using Enzymelinked immunosorbent assay (ELISA) kits (MyBiosource, USA) according to the specifications of the manufacturer.

\section{Statistical analysis}

The results were expressed as mean \pm standard deviation (SD); unpaired Student's $t$-test and analysis of variance (ANOVA) confirmed with Bonferroni's post hoc test were utilized to evaluate the differences between groups. A $p$-value $<0.05$ was considered for significant differences.

\section{RESULTS}

Table 1 shows that serum levels of progesterone were significantly increased in groups IV, V, and VI $(72 \%, 225 \%$, and $268 \%$, respectively) compared to the corresponding levels in group I; while progesterone levels were not significantly changed in groups II and III ( $p>0.05)$ versus controls. Moreover, serum levels of estradiol in groups III and V were found to be significantly lower than those obtained in group I (79\% and 43\%). Meanwhile, group VI demonstrates a significantly higher level of serum estradiol compared to all other groups $(p<0.05)$. Additionally, Table 1 shows that the level of TNF- $\alpha$ was increased in groups II, III, V, and VI $(636 \%, 726 \%, 795 \%$, and $213 \%$, respectively) compared to group I. However, serum TNF- $\alpha$ level in group IV was not significantly changed versus the controls $(p<0.05)$ and found to be significantly lower than that reported in other groups. A similar pattern of changes was reported in serum C-reactive protein (CRP) levels, where groups IV and VI demonstrated significantly lower levels compared to the other groups, but they are still significantly higher than that of the control group (43\% and 36\%, respectively). In Figure 1, serum ALT activity was significantly elevated in all test groups compared to the controls. However, serum ALT levels in groups IV and VI were

Table 1. Effects of estradiol and progesterone supplementation on their serum levels and the concentrations of CRP and TNF- $\alpha$ in OVX rat challenged with SSI.

\begin{tabular}{lcccccc}
\hline \multirow{2}{*}{ Marker } & \multicolumn{5}{c}{ Animal groups $(\boldsymbol{n}=\mathbf{1 0})$} \\
\cline { 2 - 7 } & Group I & Group II & Group III & Group IV & Group V & Group VI \\
\hline S. Progesterone $(\mathrm{ng} / \mathrm{ml})$ & $11.6 \pm 1.4^{\mathrm{a}}$ & $11.5 \pm 1.8^{\mathrm{a}}$ & $10.1 \pm 1.1^{\mathrm{a}}$ & $19.9 \pm 3.6^{* \mathrm{~b}}$ & $37.7 \pm 5.1^{* \mathrm{c}}$ & $38.4 \pm 5.0^{* \mathrm{c}}$ \\
S. Estrogen $(p \mathrm{~g} / \mathrm{ml})$ & $49.6 \pm 5.8^{\mathrm{a}}$ & $41.7 \pm 6.8^{\mathrm{a}}$ & $10.5 \pm 1.4^{* \mathrm{~b}}$ & $40.5 \pm 5.7^{\mathrm{a}}$ & $28.3 \pm 3.2^{* \mathrm{c}}$ & $60.2 \pm 7.9^{* \mathrm{~d}}$ \\
S. CRP $(\mu \mathrm{g} / \mathrm{ml})$ & $1.4 \pm 0.4^{\mathrm{a}}$ & $2.6 \pm 0.3^{* \mathrm{~b}}$ & $3.9 \pm 0.5^{* \mathrm{c}}$ & $2.0 \pm 0.22^{* \mathrm{~b}}$ & $4.9 \pm 0.3^{* \mathrm{c}}$ & $1.9 \pm 0.3^{* \mathrm{~b}}$ \\
S. TNF- $\alpha(p \mathrm{~g} / \mathrm{ml})$ & $11.5 \pm 1.2^{\mathrm{a}}$ & $84.6 \pm 4.1^{* \mathrm{~b}}$ & $95.5 \pm 4.2^{* \mathrm{c}}$ & $14.5 \pm 0.8^{\mathrm{a}}$ & $103.5 \pm 6.0^{* \mathrm{~d}}$ & $36.1 \pm 2.8^{* \mathrm{e}}$ \\
\hline
\end{tabular}

Values are expressed as mean $\pm \mathrm{SD} ; \mathrm{n}$ : number of rats in each group; * significantly different compared to the controls (unpaired $t$-test, $p<0.05$ ); values with non-identical superscripts (a,b,c,d,e) among different groups are significantly different (ANOVA, $p<0.05)$. 
found to be significantly lower than the other test groups (II, III, and V). Figure 2 indicates that the activity of caspase- 3 was significantly elevated in all test groups compared with the sham-operated without the SSI group of rats $(p<0.05)$. The highest levels of caspase- 3 were reported in groups II and III, and the lowest degree of elevation in caspase-3 level was reported in group III. There was no significant difference in the liver tissue level of caspase- 3 between groups $\mathrm{V}$ and VI $(p>0.05)$. Regarding the influence of estradiol and progesterone supplementation to OVX rats challenged with SSI on the expression of COX-II in the liver, Figure 3 shows that COX-II expression was significantly elevated in all test groups compared to the control group, and the highest levels of expression were reported in groups II and III. Meanwhile, the levels of COX-II expression in groups V and VI were found non-significantly different $(p>0.05)$. Additionally, the

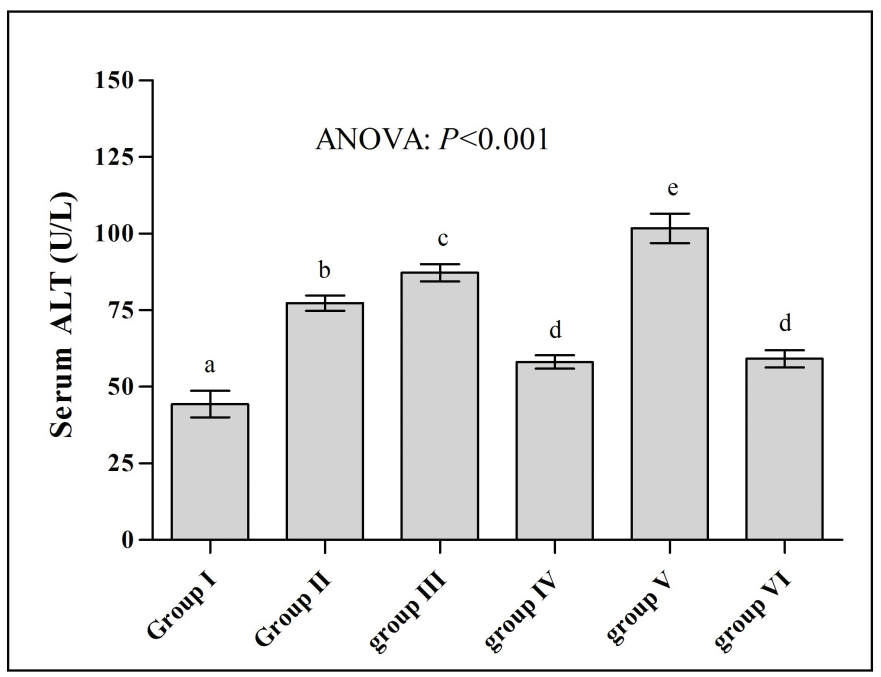

Figure 1. Effects of estradiol and progesterone supplementation on serum ALT levels in OVX rat challenged with SSI. Number of rats: 10 in each group; values with non-identical letters $(\mathrm{a}, \mathrm{b}, \mathrm{c}, \mathrm{d}, \mathrm{e})$ are significantly different (ANOVA, $p<0.05$ ).

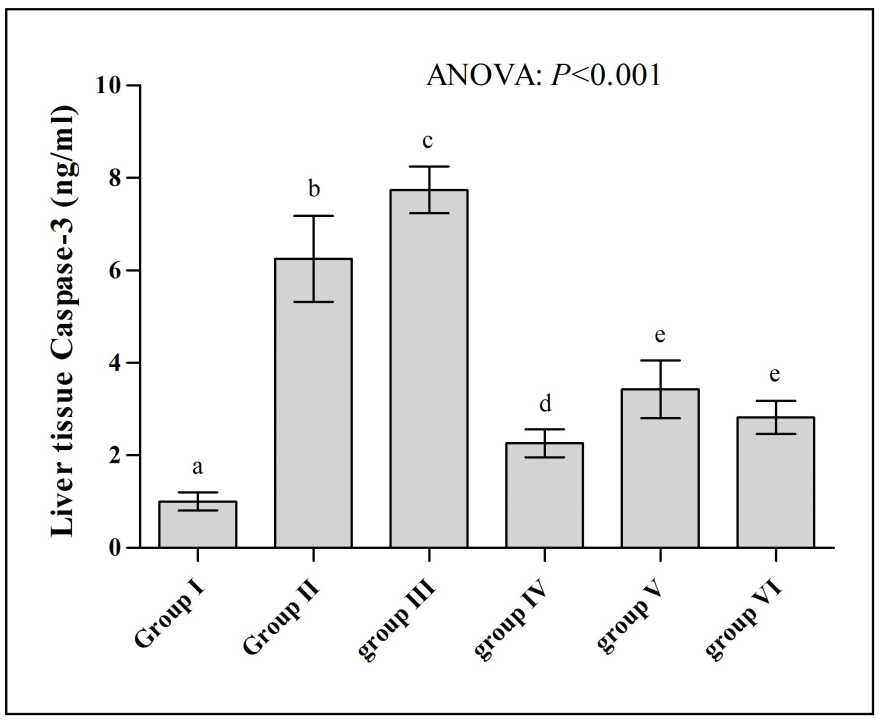

Figure 2. Effects of estradiol and progesterone supplementation on liver tissue caspase-3 activity in OVX rat challenged with SSI. Number of rats: 10 in each group; values with non-identical letters $(\mathrm{a}, \mathrm{b}, \mathrm{c}, \mathrm{d}, \mathrm{e})$ are significantly different (ANOVA, $p<0.05$ ). expression of iNOS in the liver tissue was significantly elevated in groups II, III, and V versus the controls (Fig. 4). Meanwhile, iNOS expression in groups IV and VI was not significantly different from that reported in the control group and found to be comparable when compared with each other $(p>0.05)$.

\section{DISCUSSION}

In this study, Table 1 shows that SSI induction was associated with a significant reduction in serum estradiol level in group III, which can be attributed to the excessive production of NO that leads to direct inhibition of Gonadotropin-releasing hormone (GnRH) synthesis (Herrington et al., 2001). Moreover, previous reports suggested that the pro-inflammatory mediators directly inhibited the process of steroidogenesis in the ovaries (Son and Roby,

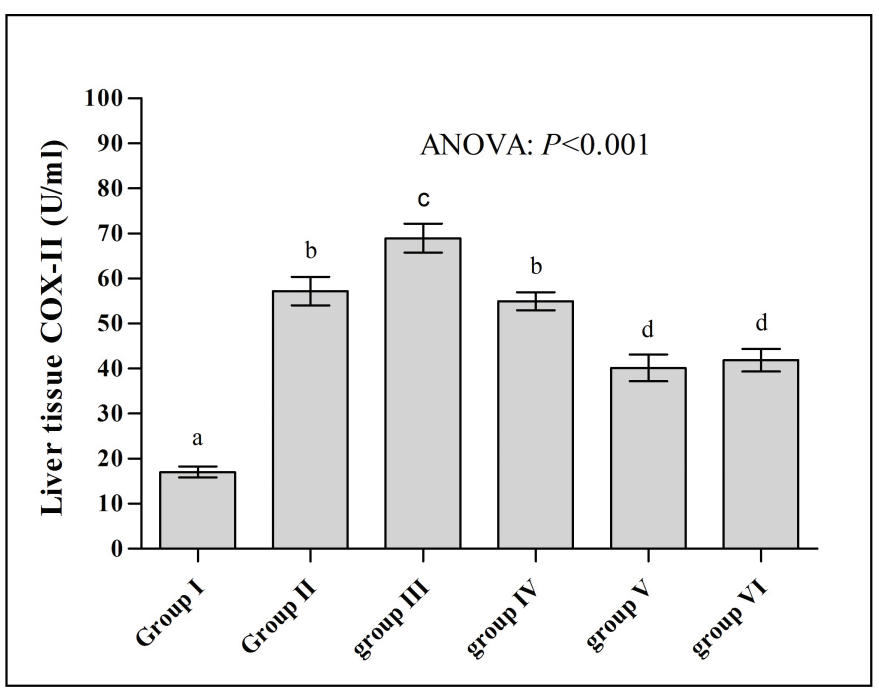

Figure 3. Effects of estradiol and progesterone supplementation on liver tissue COX-II levels in OVX rat challenged with SSI. Number of rats: 10 in each group; values with non-identical letters $(\mathrm{a}, \mathrm{b}, \mathrm{c}, \mathrm{d})$ are significantly different (ANOVA, $p<0.05$ )

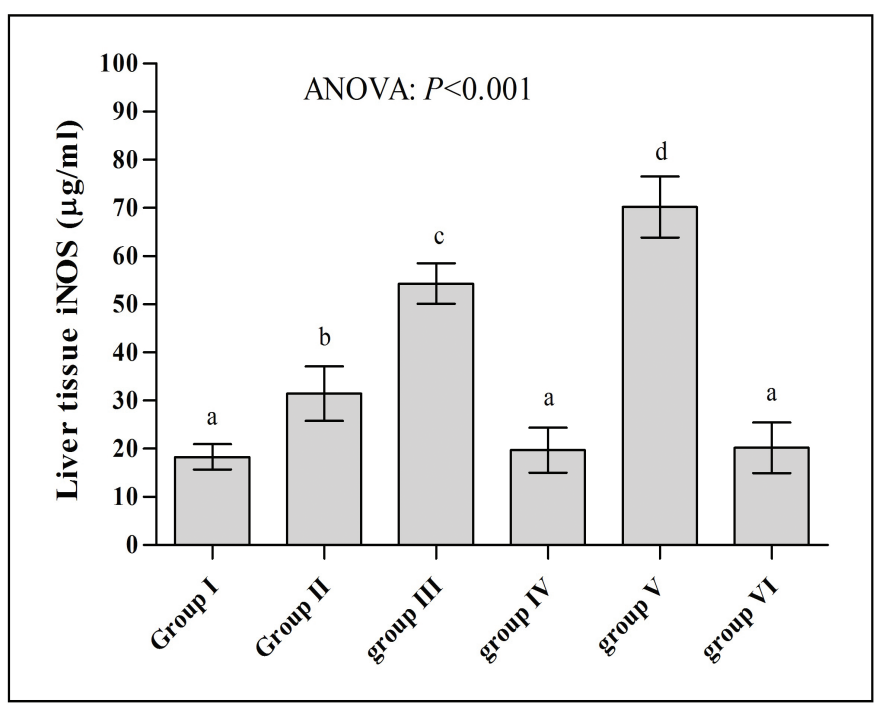

Figure 4. Effects of estradiol and progesterone supplementation on liver tissue iNOS levels in OVX rat challenged with SSI. Number of rats: 10 in each group; values with non-identical letters $(\mathrm{a}, \mathrm{b}, \mathrm{c}, \mathrm{d})$ are significantly different (ANOVA, $p<0.05$ ). 
2006), which may explain the decrease in serum estradiol levels in OVX rats challenged with SSI compared with negative and positive control groups. The supplementation of the OVX rats with daily doses of estradiol and progesterone (group VI) resulted in increased serum levels of both hormones that may achieve the range of the diestrus/ proestrus levels found in normal cycling rats (Sunday et al., 2006). However, the reported higher concentrations may explain the positive effect of estradiol supplementation on the peripheral mechanisms that control progesterone synthesis (Sunday et al., 2006). This study reported highest levels of TNF- $\alpha$, CRP, ALT, and iNOS expression in the OVX rats treated with progesterone and challenged with septic inflammation (group V), while the highest caspase-3 and COXII expression were reported in group III compared to the control group (group I). Meanwhile, the groups treated with estradiol or its combination with progesterone (groups IV and VI) showed a marked reduction of these parameters compared to both the control and the other groups. It has been reported that progesterone enhances both the susceptibility to septic challenge and the associated inflammatory responses, which may lead to severe infections and the aggravation of the inflammatory changes (Kautschic et al., 2000). However, the combination of progesterone with estradiol in this study revealed the predominant anti-inflammatory effects of the estradiol in this model. Conflicting data with our findings were observed where others (Jiang et al., 2009) reported the decrease in TNF- $\alpha$ expression by progesterone in a rat model of brain injury. Meanwhile, Roof and Hall, (2000) revealed that progesterone may also decrease the oxidative stress by its membrane-stabilizing effect. This might be attributed to the differences in the experimental model and methods of analysis. Additionally, estradiol protects the Central nervous system (CNS) against neurotoxic stimuli and decreases the TNF- $\alpha$ expression in female rats treated with a combination of progesterone and estradiol (Vegeto et al., 2008). The extent of liver damage was influenced by the gender, where lower serum ALT was reported in female rats with hepatotoxicity versus the males of the same model (El-Toukhy et al., 2012); this came in tune with our finding regarding the role of estradiol supplementation on the severity of liver damage due to a septic shock. Moreover, it has been reported that estradiol replacement decreases the severity of hepatic damage in OVX rats compared to those with intact ovaries (Yin et al., 2000). This finding does not agree with ours, where serum ALT levels were high in groups II and III and peaked in group V, while lower levels were obtained in groups IV and VI supporting the assumption of the antiinflammatory role of estradiol (Shivers et al., 2015). The expression of iNOS was enhanced in OVX rats 2-6 weeks post-operation compared with sham-operated rats (Lee et al., 2005). The result of this study was in tune with this finding, where liver tissue expression of iNOS was significantly higher than that reported in the shamoperated rats. In this regard, the administration of $17-\beta$ estradiol inhibits the expression of iNOS mRNA in OVX rats challenged with lipopolysaccharide (Yallampalli and Dong, 2000). Meanwhile, Yilmaz et al. (2013) reported that iNOS expression can be inhibited by estradiol supplementation (Yilmaz et al., 2013). The differential effects of progesterone and estradiol on the expression of iNOS in different tissues seem to be controversial according to many studies. In this regard, it has been mentioned that both progesterone- and estradiol-enhanced iNOS expression supporting the involvement of those hormones in the regulation of iNOS expression (Ogando et al., 2003). Our finding in this respect was in tune with the many data reported by other researchers (Buhimschi et al., 2000; Hassouna et al., 2014) regarding the negative effect of progesterone on the hepatic NO levels, whereas Al-Hijji et al. (2001) reported the stimulatory effect of progesterone administration on uterine NOS activity (Al-Hijji et al., 2001). These variable effects on iNOS expression could be attributed to the use of different types of cell preparations or animal models. In experimental animals, previous data indicated that the administration of estradiol to OVX rats causes overexpression of uterine COX-II mRNA compared to the use of progesterone alone (Engstrøm, 2001). Regarding the impacts on COX-II, the presented data were in tune with the previous finding; where lowest COX-II expression was observed in group V supplemented with progesterone alone and a little bit higher in group VI after supplementation with estradiol/ progesterone combination. However, both findings conflicted with that reported by Hassouna et al. (2014) that suggested a generalized decrease in COX-II expression in the liver tissues during estradiol supplementation in physiological doses. This study revealed the reduction of liver tissue caspase- 3 expression in the groups treated with estradiol, progesterone, or their combination. A similar finding mentioned that treatment with progesterone was associated with a decreased caspase- 3 activity (Karatepe et al., 2012). Moreover, Da et al showed that estradiol downregulates the expression of caspase-3 in the lacrimal and submandibular glands of OVX rats due to the anti-apoptotic and antioxidant effects (Da et al., 2015). In this regard, Xue et al. (2017) attributed the progesterone-induced reduction of caspase-3 expression to the inhibition of the NF- $\kappa$ B pathway in the OVX rats (Xue et al., 2017).

\section{CONCLUSION}

The supplementation of estradiol in OVX rats challenged with SSI significantly attenuated the systemic and liver inflammatory and apoptotic markers of acute systemic inflammation. Meanwhile, the supplementation with progesterone doses exacerbates the effects of the inflammatory mediators and increases the tendency of apoptosis in the liver tissues.

\section{ACKNOWLEDGMENT}

The authors thank Al-Rafidain University College for supporting the project.

\section{CONFLICT OF INTEREST} interest exists.

The authors have declared that no competing

\section{FUNDING}

No specific fund received.

\section{REFERENCES}

Aksoy AN, Toker A, Celik M, Aksoy M, Halici Z, Aksoy H. The effect of progesterone on systemic inflammation and oxidative stress in the rat model of sepsis. Indian J Pharmacol, 2014; 46(6):622-6.

Al-Hijji J, Larsson I, Batra S. Effect of ovarian steroids on nitric oxide synthase in the rat uterus, cervix and vagina. Life Sci, 2001; 69:1133-42.

Angstwurm MW, Gaertner R, Schopohl J. Outcome in elderly patients with severe infection is influenced by sex hormones but not gender. Crit Care Med, 2005; 33:2786-93.

Bohannon J, Guo Y, Sherwood ER. The role of natural killer cells in the pathogenesis of sepsis: the ongoing enigma. Crit Care, 2012; 16(6):185.

Buhimschi IA, Yallampalli C, Buhimschi CS, Saade GR, Garfield RE. Distinct regulation of nitric oxide and cyclic guanosine monophosphate 
production by steroid hormones in the rat uterus. Mol Hum Reprod, 2000; 6:404-14.

Cushman M, Legault C, Barrett-Conner E, Stefanick ML, Kessler C, Judd HL, Sakkinen PA, Tracy RP. Effect of postmenopausal hormones on inflammation-sensitive proteins: the Postmenopausal Estrogen/Progestin Interventions (PEPI) study. Circulation, 1999; 100:717-22.

Da Y, Niu K, Wang K, Cui G, Wang W, Jin B, Sun Y, Jia J, Qin L, Bai W. A comparison of the effects of estrogen and Cimicifuga racemosa on the lacrimal gland and submandibular gland in ovariectomized rats. PLoS One, $2015 ; 10(3): \mathrm{e} 0121470$.

Dellinger RP, Levy MM, Carlet JM, Bion J, Parker MM, Jaeschke R, Reinhart K, Angus DC, Brun-Buisson C, Beale R, Calandra T. Surviving Sepsis Campaign: international guidelines for the management of severe sepsis and septic shock: 2008. Crit Care Med, 2008; 36:296-327.

El-Toukhy SE, Alnahdi H, Ayaz N, Hamza AH. Hormonal modulation of ginseng against hepatotoxicity induced in experimental animals. Int J Acad Res, 2012; 4(6):174-80.

Engstrøm T. The regulation by ovarian steroids of prostaglandin synthesis and prostaglandin-induced contractility in non-pregnant rat myometrium. Modulating effects of isoproterenol. J Endocrinol, 2001; 169(1):33-41.

Fink MP, Heard SO. Laboratory models of sepsis and septic shock. Surg Res, 1990; 49(2):186-96.

Gewurz H, Siegel J, Fiedle B. C-reactive protein and the acute phase response. Adv Intern Med, 1982; 27:345-72.

Hassouna A, Obaia E, Marzouk S, Rateb M, Haidara M. The role of sex hormones in induced-systemic inflammation in female albino rats. Acta Physiol Hung, 2014; 101(1):112-27.

Herrington DM, Brosnihan KB, Pusser BE, Seely EW, Ridker PM, Rifai N, MacLean DB. Differential effects of $\mathrm{E}$ and raloxifene on C-reactive protein and other markers of inflammation in healthy postmenopausal women. J Clin Endocrinol Metab, 2001; 86:4216-22.

Jedynak M, Siemiątkowski A, Rygasiewicz K. Molecular basis of sepsis development. Anaesthesiol Intensive Ther, 2012; 44(4):221-5.

Jiang C, Wang J, Li X, Liu C, Chen N, Hao Y. Progesterone exerts neuroprotective effects by inhibiting inflammatory response after stroke. Inflamm Res, 2009; 58(9):619-24.

Karatepe O, Altiok M, Battal M, Kamali G, Kemik A, Aydin T, Karahan S. The effect of progesterone in the prevention of the chemically induced experimental colitis in rats. Acta Cir Bras, 2012; 27(1): 23-9.

Kautschic C, Zhou F, Murdin AD, Wira CR. Effects of estradiol and progesterone on susceptibility and early immune responses to Chlamydia trachomatis infection in the female reproductive tract. Infect Immun, 2000; 68(7):4207-16.

Lee YM, Cheng PY, Hong SF, Chen SY, Lam KK, Sheu JR, Yen $\mathrm{MH}$. Oxidative stress induces vascular heme oxygenase-1 expression in ovariectomized rats. Free Radic Biol Med, 2005; 39(1):108-17.

Lowes DA, Webster NR, Murphy MP, Galley HF. Antioxidants that protect mitochondria reduce interleukin- 6 and oxidative stress improves mitochondrial function and reduces biochemical markers of organ dysfunction in a rat model of acute sepsis. Br J Anaesth, 2013; 110(3):472-80.

Marshall JC. Inflammation, coagulopathy, and the pathogenesis of multiple organ dysfunction syndrome. Crit Care Med, 2001; 29:99-106.

Mizutani A, Okajima K, Uchiba M, Isobe M, Harada N, Mizutani $\mathrm{S}$, Noguchi T. Anti-thrombin reduces ischemia-reperfusion-induced renal injury in rats inhibiting leukocyte activation through the promotion of prostacyclin production. Blood, 2003; 101(8):3029-36.

Ogando D, Farina M, Ribeiro ML, Perez Martinez S, Cella M, Rettori V, Franchi A. Steroid hormones augment nitric oxide synthase activity and expression in rat uterus. Reprod Fertil Dev, 2003; 15(5):269-74.
Roof RL, Hall ED. Gender differences in acute CNS trauma and stroke: neuroprotective effects of estrogen and progesterone. J Neurotrauma, 2000; 17(5):367-88.

Rosano GM, Webb CM, Chierchia S, Morgani GL, Gabraele M, Sarrel PM, de Ziegler D, Collins P. Natural progesterone, but not medroxyprogesterone acetate, enhances the beneficial effect of estrogen on exercise-induced myocardial ischemia in postmenopausal women. J Am Coll Cardiol, 2000; 3(6):2154-9.

Shivers KY, Amador N, Abrams L, Hunter D, Jenab S, QuiñonesJenab V. Estrogen alters baseline and inflammatory-induced cytokine levels independent from hypothalamic-pituitary-adrenal axis activity. Cytokine, 2015; 72(2):121-29.

Son DS, Roby KF. Interleukin-1alpha-induced chemokines in mouse granulosa cells: impact on keratinocyte chemo-attractant chemokine, a CXC subfamily. Mol Endocrinol, 2006; 20:2999-3013.

Sunday L, Tran MM, Krause DN, Duckles SP. Estrogen and progestagens differentially modulate vascular pro-inflammatory factors. Am J Physiol Endocrinol Metab, 2006; 291:E261-7.

Szalay L, Shimizu T, Suzuki T, Hsieh YC, Choudhry MA, Schwacha MG, Bland KI, Chaudry IH. Androstenediol administration after trauma-hemorrhage attenuates inflammatory response, reduces organ damage, and improves survival following sepsis. Am J Physiol Gastrointest Liver Physiol, 2006; 291(2):G260-6.

Tsai HW, Legan SJ. Loss of luteinizing hormone surges induced by chronic estradiol is associated with decreased activation of gonadotropinreleasing hormone neurons. Biol Reprod, 2002; 66:1104-10.

Vegeto E, Benedusi V, Maggi A. Estrogen anti-inflammatory activity in the brain: a therapeutic opportunity for menopause and neurodegenerative diseases. Front Neuroendocrinol, 2008; 29(4):507-19.

Wakatsuki A, Ikenoue N, Shinohara K, Watanabe K, Fukaya T. Effect of lower dosage of oral conjugated equine estrogen on inflammatory markers and endothelial function in healthy postmenopausal women. Arterioscler Thromb Vasc Biol, 2004; 24:571.

Xue XT, Kou XX, Li CS, Bi RY, Meng Z, Wang XD, Zhou YH, Gan YH. Progesterone attenuates temporomandibular joint inflammation through inhibition of the NF-kB pathway in ovariectomized rats. Sci Rep, 2017; 7(1):15334.

Yallampalli C, Dong YL. Estradiol-17b inhibits nitric oxide synthase (NOS)-II and stimulates NOS-III gene expression in the rat uterus. Biol Reprod, 2000; 63:34-41.

Yilmaz O, Yagci A, Ulutas E, Sevimli A, Altunbas K, Bulbul A, Aslan R. The effect of $17 \beta$ estradiol on the expression of eNOS and iNOS in ovariectomized rat uterus. Eurasian J Vet Sci, 2013; 29(2):65-69.

Yin M, Ikejima K, Wheeler MD, Bradford BU, Seabra V, Forman DT, Sato N, Thurman RG. Estrogen is involved in early alcohol-induced liver injury in a rat enteral feeding model. Hepatology, 2000; 31(1):117-123.

\section{How to cite this article:}

Farhan SS, Mahgoub SS, Hussain SA. Effects of progesterone and estradiol on the inflammatory and apoptotic markers of ovariectomized rats challenged with acute septic systemic inflammation. J Appl Pharm Sci, 2019; 9(12):103-107. 